\title{
50 Hertz Noise by ECG Finding
}

National Cancer Institute

\section{Source}

National Cancer Institute. 50 Hertz Noise by ECG Finding. NCI Thesaurus. Code C114165.

An electrocardiographic recording showing power line interference with the

electrocardiographic signal. The artifact amplitude modulation has the same frequency

as the AC power system present $(50 \mathrm{~Hz})$. (CDISC) 